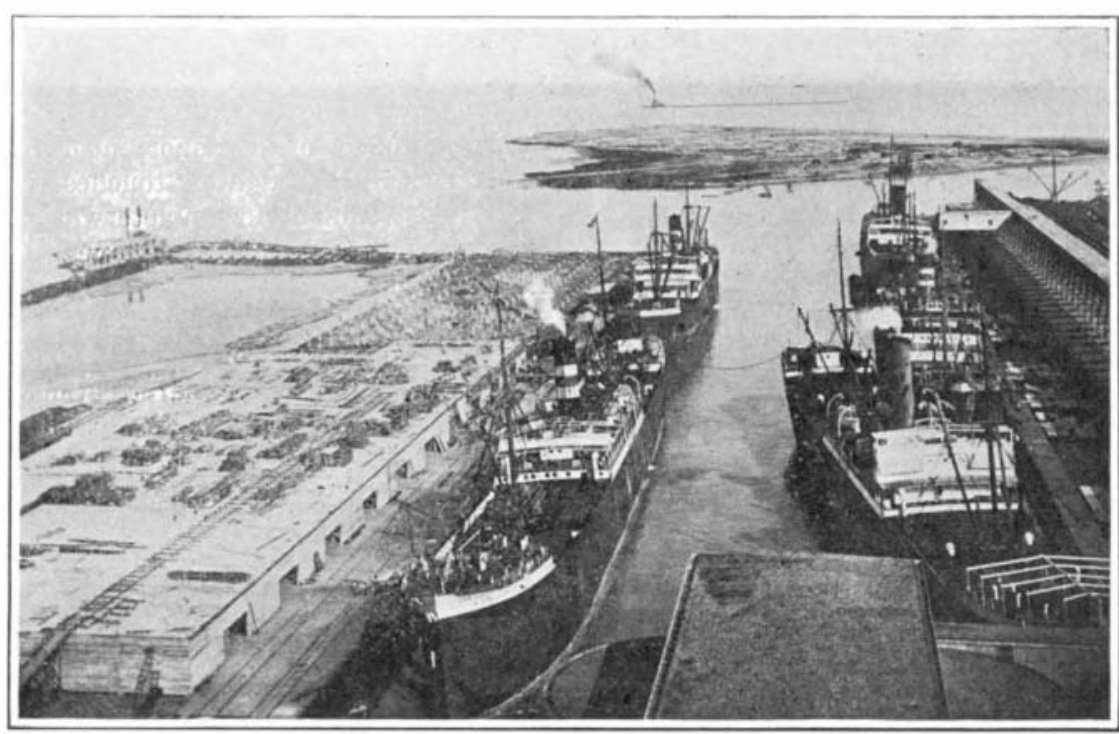

View Taken from the Top of the Grain Elevator, Showing Warehouse in Course of Construction.

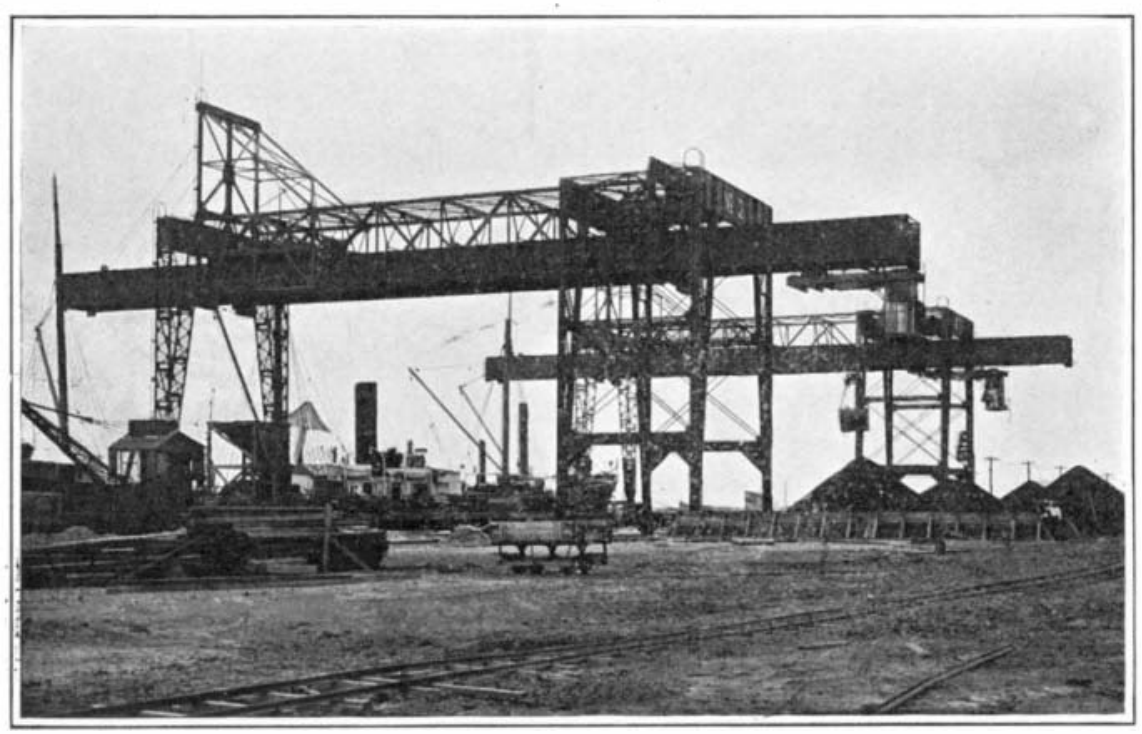

View Showing Two Traveling Bridge Cranes Discharging Coal from Steamers in the Harbor.

\title{
An Ocean Terminal for the South
}

\section{Texas City Harbor Developments}

By L. C. Talmage

Aт an expenditure of over $\$ 4,000,000$ to date there is under construction at Texas City, the mainland port on Galveston Bay, what is conceded to be the most finely equipped and best constructed ocean terminal system south of New York. Steel and reinforced concrete have been used extensively in the construction of warehouses while labor-saving machinery have been installed to eliminate in a large measure hand labor in handling freight; and as a result there has been a reduction in insurance rates and a lowering of freighthandling expenses.

The first unit of the system consists of a pier 1,200 feet long and 1,000 feet wide upon which are located four warehouses, two traveling bridge cranes, and lead and sidings, and land terminals which include four warehouses, a reinforced concrete elevator, a central power plant, and some thirty-five miles of leads and pown plant, and built in 1904, before the present fine system was undertaken, all warehouses are fireproof, minimizing fire risk and affording exceptionally low insurance rates. A number of these warehouses are equipped with laborsaving devices.

The second unit consists of a pier 900 feet long and 500 feet wide upon the north side of which is now in course of construction a double-deck reinforced concrete warehouse covering an area 155 by 880 feet. An inclined railroad will place cars on a level with the second floor. This warehouse will be duplicated on the north side of the pier and the intervening space will be occupied by tracks.

Warehouse " $B$," the only dock warehouse that is not fireproof, occupies the north side of the pier of the first unit and covers a space 80 by 1,122 feet. Surmounting the building in a grain conveyor gallery connecting with the elevator. Operating along the apron pier and connecting with the conveyor gallery is a traveling conveyor which may be set in any position allowing the discharging of grain into a vessel's hold without interfering with the looding of other cargo. One hundred feot south of Warehouse "B" is Ware- house "C," al"steel and concrete warehouse covering an area 100 by 750 feet The foundations of this building are of concrete and the walls, supported by structural steel framework, are of cement plaster on metal lath. The roof is of concrete tile laid on steel framework. The warehouse is divided into three sections or bay by firewalls, the openings between the bays being protected by automatic fire doors. Extending through this warehouse is a Hanak system floor conveyor for the transfer of freight from shipside to any section of the building or, if desired, directly to cars. The system consists of four sections of $651 / 2$ feet each, driven by duplex drivehead at every alteinate section. There are six 6-horse-power motors along the straight lin conveyor, or two to each bay of the warehouse. Ever atternate section is equipped with a bascule section to permit the lowering of fire doors or free passage from bay to bay when the conveyor is not in use. A a maximum uniform load the conveyor will carry 220 tons of wire products or nails, the commodities handled exclusively in this warehouse. At the far end of the building there is a lateral conveyor 50 feet long which receives merchandise from the mainline conveyor an discharges directly into cars at either side of the warehouse. There are also four 12-foot portables which ar used as laterals and can be placed at any point along the mainline conveyor for diverting freight to cars alongside the warehouse. The motors operating these conveyors are 230-volt direct current, compound wound are connected to run in either direction and are wired to the main current in such manner that all motors may be stopped from any point along the system.

The conveyor system is supplemented by an overhead crane system, one crane in each of the three bays. These cranes have a lifting capacity of 2 tons each and operate on rails built along the sides of the building directly under the cross beams of the roof. The forward movement of each crane is 250 feet, or the length of the bay, and the hoist carriage, has a side movement of 100 , or the width of the building. Thus, freight may be picked up at any point in the bay and transferred to any other point, piling in tiers to a height of 22 feet from the floor level. In handling barbed wire or rolls of fencing hooks are generally used, while nails are handled by means of a magnet. One 60-horsepower motor operates the hoist while two 20-horsepower motors drive the crane along the tracks.

One hundred and ten feet south of Warehouse "C" is Warehouse " $D$," a duplicate of " $C$ " except that as yet it has not been equipped with cranes and conveyors. 118 by 522 feet in dimensions and built of structural steel and corrugated iron. The south roof of this warehouse is equipped with hatches with sliding doors, which openings permit the transfer of freight from the interior to a ship's hold by means of two traveling dock cranes operating along the south side of the pier. These cranes are of special design and travel on three ground. The distance between the dock leg of each crane and the middle leg is 94 feet, the intervening space being occupied by four railroad tracks. The distance from the middle leg and the third leg is 26 feet. The supporting bridge is designed as a truss and carries a plate girder boom 112 feet in lenoth. This boom, in connection with the hoisting carriage operating beneath, has a span of 200 feet. The hoisting crane has a lifting capacity of 11,000 pounds. The hoist carriage carries the operator housed in a cage, from which all movements of the crane are directed. The crane is driven by a direct-current, main-haul, 100horse-power motor, and the auxiliary haul or lifting movement is move- 20 - is control the movement along the tracks. A compressed air system operates the brakes that check every movement of the crane.

These cranes are used for handling heavy commodities such as rails and structural steel, coal, shell, ore, timbers, and cotton. In handling steel products a magnet is used.

The land warehouses are four in number. One of

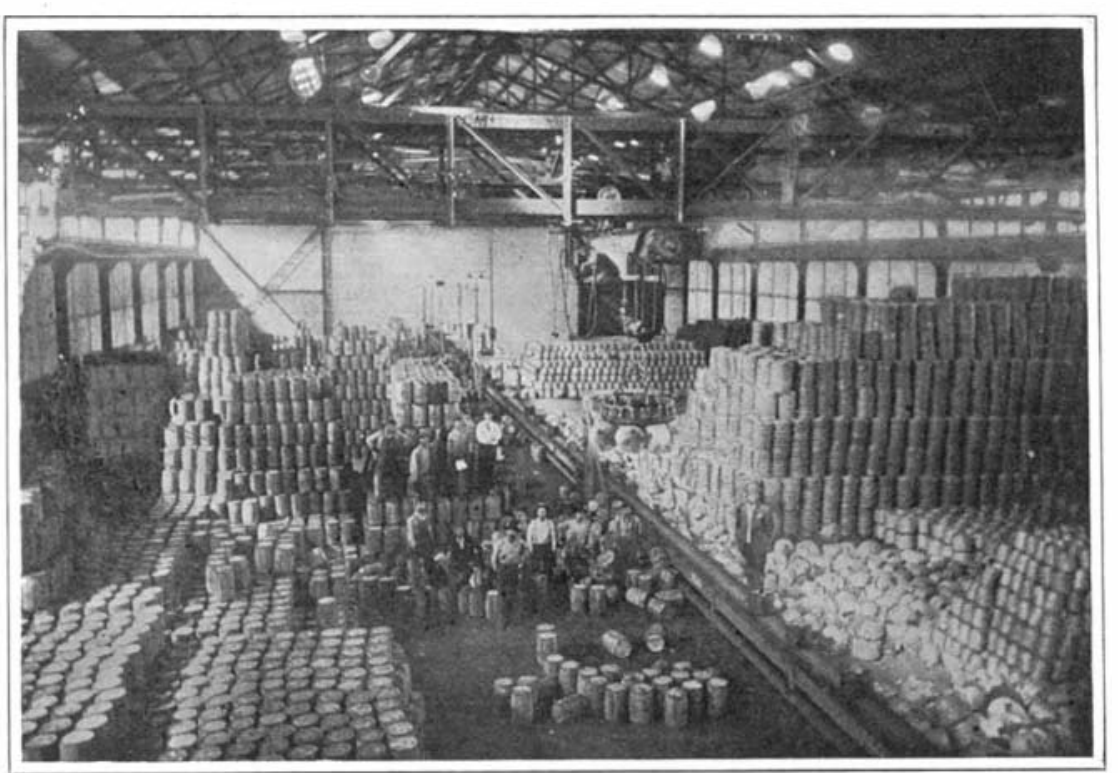

Interior of Warehouse, Showing Overhead Crane Handling Materials With a Magnet.

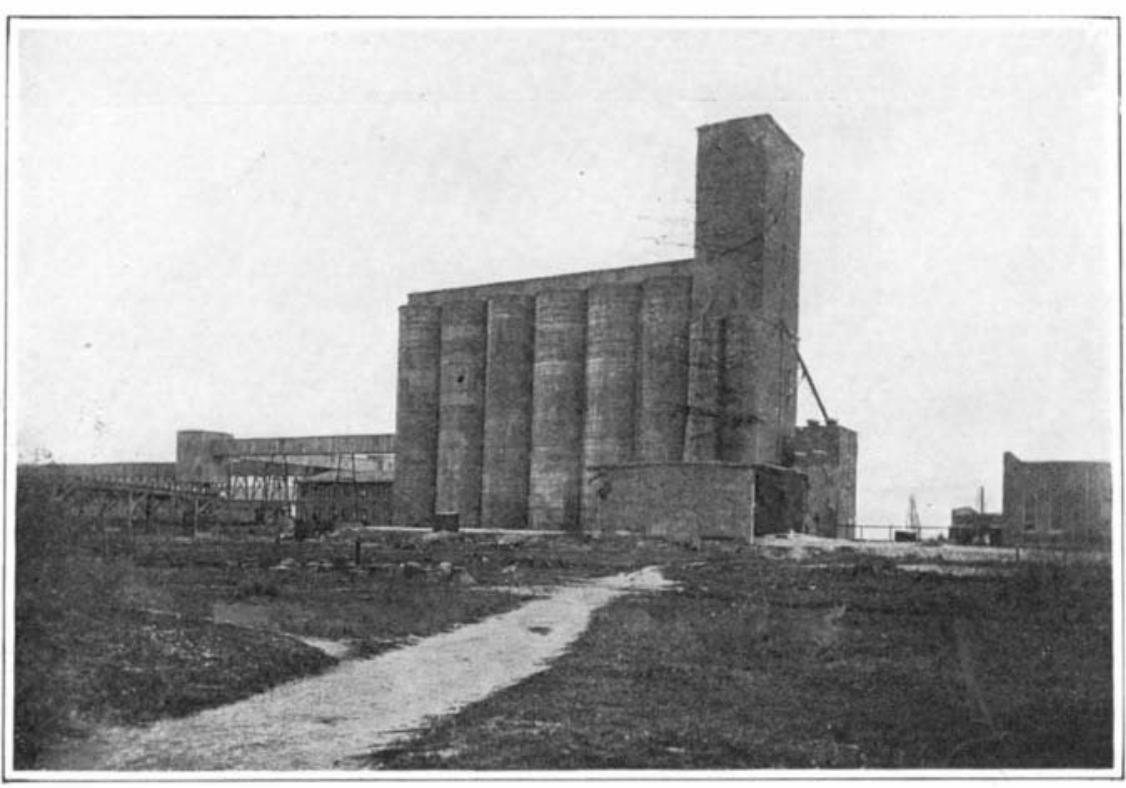

Reinforced Concrete Grain Elevator of 500,000 Bushels Storing Capacity. 
these, built in 1904, is used for the concentration of cotton and covers a space 80 by 1,200 feet. It is divided into sections of 120 feet by firewalls, equipped with automatic fire doors. The other four warehouses are each 100 by 250 feet, built on concrete foundations with superstructure of cement plaster on metal lath sup ported by steel framework. The roofs are of cement tile supported by steel framework. The floors are elevated four feet bringing them on a level with car floors. One track extends through the warehouse Each of these warehouses is equipped with an overhead traveling crane of the same type as those used in Warehouse "C." By means of these cranes cotton and other commodities can be piled in tiers to a height of 22 feet.
The grain elevator, which has a storage capacity of 500,000 bushels, is the first of its kind in the South and affords the cheapest insurance rate of any elevator on the Gulf. It is built of reinforced concrete and is equipped with the latest mechanical devices. There are twelve circular storage tanks 24 feet in diameter and 80 feet high, eight tanks 12 feet in diameter in the working house. Interspliced tanks occupy all the spaces between the circular tanks.

All current, both for the operation of the machiner at the docks and for lighting throughout the city, is generated at the central power plant located in the terminal yards. This plant is equipped with two directcurrent, reciprocating engines of 225 horse-power each, and two alternating-current Parsons steam turbine, one 300 kilowatts and one 625 kilowatts. Four B \& W. 250 horse-power water tube boilers complete the quipment.

As a result of the extensive construction work that has been carried) fon $^{*}$ during the past three years the commerce of the port has grown tremendously. In 1904, the first year as a port, twelve vessels arrived and departed, carrying 8,712 tons of cargo. In 1912, three hundred and ninety-six vessels arrived and departed, carrying 463,191 tons of cargo. The foreign ment of cotton was 728,136 bales, valued at $\$ 43,293,982$, and 628,337 bushels of wheat, which, with the flour movement, reached in value $\$ 720,571$. The total export movement was valued at $\$ 44,685,601$.

\section{Progress in a Puzzling Malady*}

\section{The Stable Fly as the Carrier of Infantile Paralysis}

\section{By Charles T. Brues}

The fact that several common human diseases are spread through the agency of blood-sucking insects is now quite familiar to the general public, in spite of the very short space of time which has elapsed since any disease was shown to be specifically insect-borne.

Nevertheless, it is difficult to realize that scarcely more than a decade separates the present from the time when yellow fever and malaria were removed from the category of mysterious maladies whose method of spread was utterly unknown. These, together with splenetic or "Texas" fever of cattle, formed a nucleus about which has been grouped a number of other human and animal diseases all of which are transmitted by specific insects or closely related animals. Certain mosquitoes, blood-sucking flies, ticks, lice and bugs have thus been shown to be concerned in the spread of disease and their pernicious activities have been carefully investigated from the standpoint of public health.

The most recent addition to the category of insectborne diseases is anterior poliomyelitis or acute epidemie poliomyelitis, more commonly known as infantile paralysis.

During the past several years a suspicion has been developing among students of this disease that it, too, might result from infection carried by some insect, and the Massachusetts State Board of Health decided to have this possibility investigated during the summer of 1911 , under the direction of Dr. Mark W. Richardof 1911 , under the direction of Dr. Mark W. Richard-
son, the secretary of the board. Accordingly, as entomologist, the present writer in company with Dr. Philip A. E. Sheppard, who was investigating for the State health authorities the epidemiology of the disease, attempted to determine by observation in the field whether any special insects might appear to be associated with the cases which occurred that season in ciated with the cases which occurred that season in
eastern Massachusetts. Working in this way, it was possible to eliminate many insects which might otherwise have been suspected as carriers, and as the season's work progressed the suspicion gradually grew more and more strong that the common stable fly (Stomoxys calcitrans) might be the insect concerned, especially as the seasonal history, distribution and habits of this blood-sucking fly appeared to fit in closely habits of this blood-sucking fly appeared to fit in
with the observed epidemiology of the disease.

During the past summer of 1912 Prof. M. J. Rosenau of the Harvard Medical School, who was already thoroughly familiar with the disease, and the present writer, undertook to determine experimentally with monkeys, whether the stable fly could act as a vector for the virus of poliomyelitis. The successful outcome of this work has very recently been announced in a paper $^{2}$ describing the experiments in which healthy monkeys developed poliomyelitis after having been bitten by stable flies which had previously fed upon the blood of monkeys infected with the disease. These results have been further confirmed by Drs. Anderson and Frost of the Public Health and Marine Hospital Service, ${ }^{3}$ who repeated the same experiments and Service, ${ }^{3}$ who repeated the same experiments and
definitely proved that the disease develops in monkeys

$$
\text { * Reproduced from Science Conspectus. }
$$

Brues, C. T., and P. A. E. Sheppard. "The Possible Etiological Relation of Certain Biting Insects to the Spread of cute Epidemic Poliomyelitis." Bull. Mass. St. Bd. Health, December, 1911, pp. 46 to 48 (abstract) ; Journ. Econ.
mology, Vol. 5, pp. 305 to 324 , August, 1912 (full report).

Rosenau, M. J., and C. T. Brues. "Some Experimental - bservations Upon Monkeys Concerning the Transmission of Bull. Mass. St. Bd. Health, September, 1912, pp. 314 to 317. ${ }^{8}$ Anderson, J. F., and W. H. Frost. "Transmission of Poliomyelitis by Means of the Stable Fly (Stomoxys calcitrans). Public Health Rep
1735 (October 25th, 1912). which have been bitten by stable flies that have pre viously fed on monkeys suffering from poliomyelitis.

The stable fly is a small insect very much like the ordinary house fly, to which it is closely related, and for which it is frequently mistaken on account of its size, rather similar coloration and common occurrence in the neighborhood of human habitations. In spite

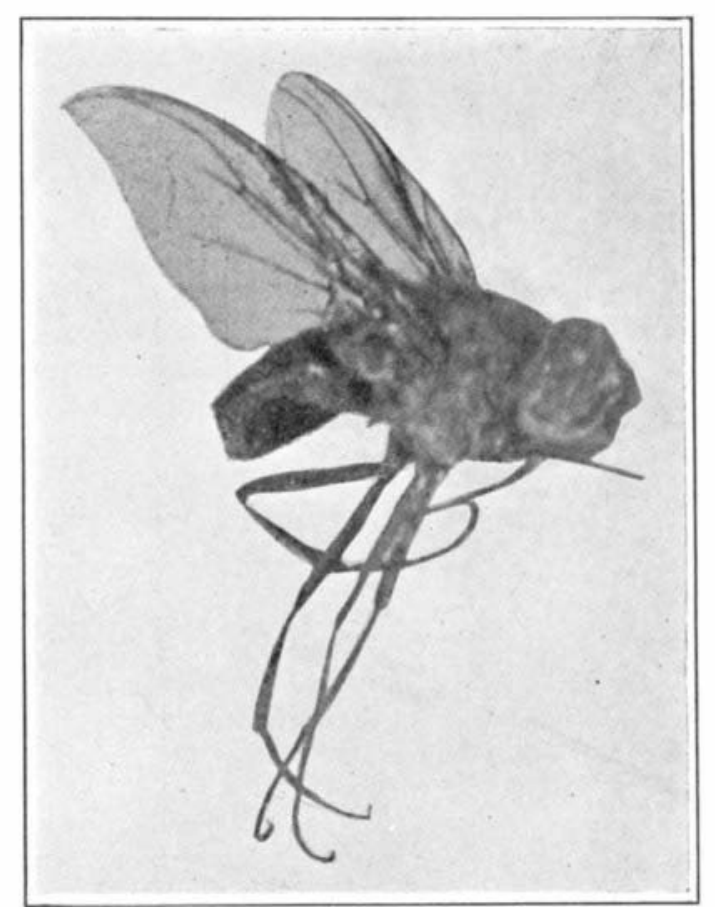

Stable Fly (Stomøxys Calcitrans) Loaned by Dr. Shep-

pard for Photographic Reproduction.

of its close similarity to the house fly, it differs in a number of important respects, both in structure, habits and distribution, and on account of its recently discovered relation to human welfare, it is worth while to mention these briefly.

The adult flies feed exclusively on blood, biting various animals and less commonly, but nevertheless quite frequently, biting persons upon parts of the body where the skin is exposed, or where the clothing is thin. Among domestic animals they occur most commonly on cattle and horses which are often much annoyed by them during the later part of the summer. On account of their feeding habits, the flies are more com mon in rural districts where the number of animals is large, or in the case of more thickly populated districts, in the neighborhood of stables or places where large domestic animals are most numerous. It is diffcult, however, to find any locality of any considerable extent under ordinary conditions where this fly does not occur. Although the flies are found in the vicinity of dwellings, they do not enter homes so commonly as does the ordinary house fly, but rather prefer to remain in the open and more especially in sunny places unless attracted elsewhere by animals or persons. Their normal food consists of mammalian blood and during its lifetime each fly feeds every two or three days, perhaps oftener, upon some warm-blooded animal, less commonly biting human beings. In fact this insect has given rise to the adage that house flies bite before a rain, which is based on the fact that persons are frequently bitten at such times by Stomoxys, which are then apt to come indoors and are mistaken for the house fly. The latter cannot pierce the skin, however, with its soft, blunt mouthparts, while a Stomoxys lcan readily insert its needle-like proboscis into the flesh.
In the writer's experience, however, Stomoxys seems to have more commonly bitten on warm, bright days. although he has been bitten even at night while writing near an electric light. Other observers have noticed that the flies often seek shelter at night. Both sexes are blood-suckers, and become greatly swollen when allowed to feed unmolested. When thus engorged they remain sluggish for a time and are apt to rest with the wings somewhat more widely spread apart than the house fly, and with the body more distinctly elevated, assuming a more sprightly attitude.

If one of the flies is examined closely from above as it rests thus, the proboscis can be seen projecting horizontally like the tip of a fine black pin directly forward from the lower edge of the head. Viewed from the side, the proboscis is seen to emerge from the lower side of the head and then bend forward at right angles for a distance about the height of the head. When sucking blood, the proboscis is straightened so that it projects directly downward from its attachment to the head. In. the resting house fly the mouthparts never project forward so as to be visible from above, and this difference will always serve to distinguish the two species at a glance.

Stomoxys appears early in the spring, but becomes much more abundant after midsummer and persists in numbers late into the fall, after the house fly has begun rapidly to disappear.

The breeding habits are much like those of the house fly. The eggs are deposited in small masses; the individual eggs are long, slender, minute objects of a pearly white color. Each hatches into a minute white maggot, slender at the head and enlarging behind to a blunt posterior end. The maggot or larva feeds rapidly, increasing in size and molting twice before changing into the pupa or resting stage from which the adult fly will emerge four or five weeks after the egg has been laid. The pupa is inclosed in an oval brown shell or puparium which is broken open at the head end to afford an exit for the emerging adult fly at the termination of the pupal stage.

The eggs are laid directly upon the materials which will serve as food for the larva. Fermenting heaps of grass, straw and similar substances, horse manure, cow dung and even garbage may serve as breeding places. The relative importance of these different foods is not yet very well known, but it seems probable that this is about in the order named. Excessive moisture is also particularly favorable for the development of the larvæ.

Stomoxys calcitrans is very widely distributed over the earth, occurring abundantly throughout Europe, North and South America, the West Indies, northern Africa, Asia, Australia, etc. It is the only member of its genus in the New World, but has a number of close relatives in the tropics of the eastern hemisphere. Whether it is native to North America or is an importation from the Old World is difficult to say, but from its wide occurrence, one would be perhaps inclined to think it native to our own region. At any rate it has been in America for a long period.

The control of Stomoxys will probably prove as difficult as that of the house fly and its eradication is obviously impossible. The ordinary flytraps and sticky flypapers which have proved so useful in dealing with the house fly are of no practical benefit in combating Stomoxys since it is not attracted to the resinous coating of the paper nor to the baits used in fly traps; as its only food in the adult condition is the blood of living animals, it is attracted only to such and cannot therefore be caught in traps. However, the "coming and going' 'flytraps devised by Prof. Hodge will undoubtedly ,catch large numbers of Stomoxys if attached 